\title{
FOREIGN DIRECT INVESTMENT, TINGKAT PENGANGGURAN, DAN KESENJANGAN PENDAPATAN \\ Studi Time Series di Indonesia Periode 2002-2015
}

\author{
MUHAMMAD RHEZA RAMADHAN
}

Direktorat Jenderal Pajak

This research is a time-series study in 2002-2015 year which aim to find the effect of Foreign Direct Investment to Unemployment Rate and Income Inequality. Base on a hand-collected sample in 2002-2015, our regression result show that Foreign Direct Investment positively associated with income inequality and did not associate with unemployment rate after controlling for inflation and government expenditure effect.

Keywords: Foreign Direct Investment, Income Inequality, Unemployment 


\section{PENDAHULUAN}

Dewasa ini, pemerintah sedang gencar-gencarnya meningkatkan investasi di dalam negeri. Salah satunya, pada industri telematika, sebagaimana diberitakan oleh antaranews.com (2017), pemerintah sedang berusaha meningkatkan investasi produksi sektor telematika yang diharapkan mampu menyerap banyak tenaga kerja Indonesia. Begitu juga di bidang energi, sebagaimana diberitakan oleh okezone.com (2017), Kementerian ESDM ingin menggalakan sektor investasi di bidang energi dengan cara menyederhanakan perizinan di bidang energi dan sumber daya mineral.

Adanya penggalakan atas investasi tersebut memperoleh hasil yang cukup memuaskan, hal ini setidaknya terlihat dari tren rasio Foreign Direct Investment (FDI) inflow per GDP yang meningkat hampir setiap tahunnya sebagaimana dapat dilihat dalam grafik di bawah ini:

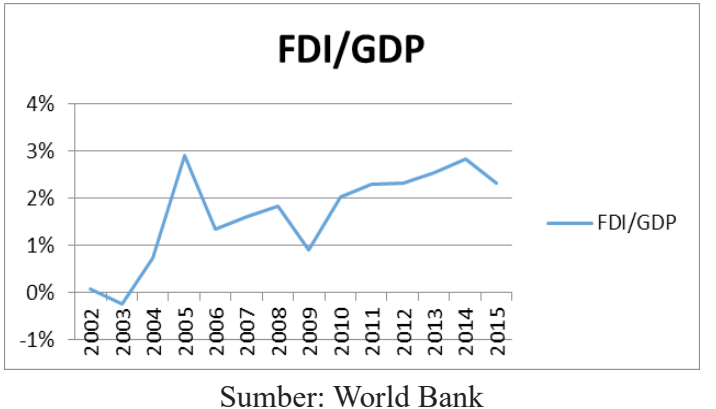

Sejak tahun 2002, tingkat pengangguran di Indonesia semakin berkurang dari tahun ke tahun sebagaimana yang dapat dilihat dalam grafik di bawah ini:

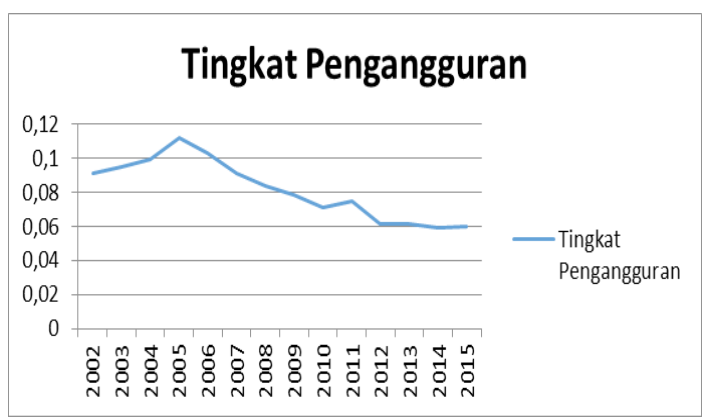

Sumber: World Bank

Hanya saja, tingkat kesenjangan pendapatan di Indonesia juga malah semakin meningkat dari tahun ke tahun sebagaimana dapat dilihat dalam grafik di bawah ini:

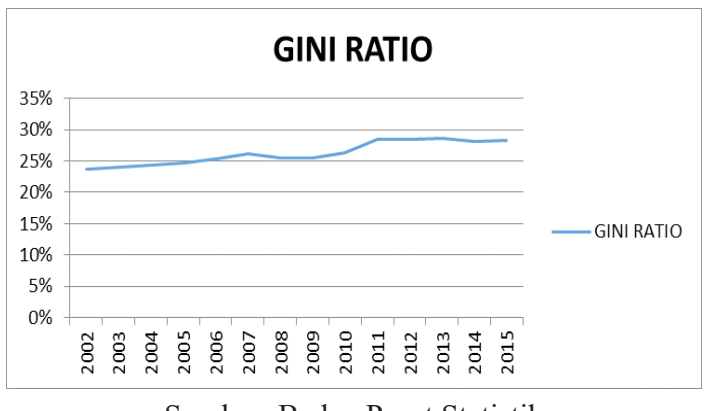

Sumber: Badan Pusat Statistik

Adanya fakta tersebut, menimbulkan pertanyaan, apakah FDI yang sedang digalakkan pemerintah ini memang dapat dengan efektif mengurangi kesenjangan pendapatan dan tingkat pengangguran? Pertanyaan ini diperkuat dengan fakta bahwa banyak perusahaan Penanaman Modal Asing yang selalu merugi di beberapa tahun berturutturut. Seperti yang diliput oleh Liputan 6 (2016).

Direktur Jenderal Pajak, Ken Dwijugiastiadi, menyatakan bahwa sebanyak 2000 PMA telah merugi selama 10 tahun. Mekar Satria Utama, Direktur Penyuluhan, Pelayanan, dan Hubungan Masyarakat, Direktorat Jenderal Pajak, sebagaimana dikutip oleh CNN Indonesia (2016), menambahkan bahwa 2000 PMA yang merugi tersebut rata-rata menggunakan modus transfer pricing. Hal ini, semakin menimbulkan pertanyaan, apakah memang pemerintah perlu menggalakkan FDI jika memang tidak mampu memberi nilai tambah kepada Indonesia? Adanya pertanyaan-pertanyaan tersebut, penulis tertarik untuk melakukan penelitian mengenai pengaruh FDI terhadap tingkat pengangguran dan kesenjangan pendapatan

Penelitian ini bertujuan untuk melihat apakah FDI memang memberi pengaruh positif kepada Indonesia, khususnya dalam hal berkurangnya tingkat pengangguran dan kesenjangan pendapatan, atau sebaliknya tidak berpengaruh atau malah memberi pengaruh negatif kepada Indonesia.

\section{TINJAUAN PUSTAKA}

Kesenjangan pendapatan merupakan ukuran ketimpangan relatif pendapatan antar golongan 
masyarakat. Ketimpangan pendapatan ini dapat diukur dengan menggunakan GINI ratio (Wahyuni et al., 2014).

\section{Pengaruh FDI terhadap Ketimpangan Pendapatan}

Banyak penelitian yang telah dilakukan untuk mencari hubungan antara FDI dengan ketimpangan pendapatan (Choi, 2006). Beberapa penelitian mengatakan bahwa adanya FDI dapat mengurangi ketimpangan pendapatan karena dapat menyerap tenaga kerja tidak terdidik dalam suatu negara (Deardorff dan Stern, 1994). Kemudian, penelitian yang lainnya menyatakan bahwa FDI dapat meningkatkan pertumbuhan ekonomi yang dapat berpengaruh positif terhadap keseluruhan perekonomian dalam suatu negara yang implikasinya adalah dapat mengurangi ketimpangan pendapa$\tan$ (Tsai, 1995).

Sebaliknya, terdapat pula penelitian yang menyatakan bahwa FDI dapat meningkatkan ketimpangan pendapatan di suatu negara. Penelitianpenelitian tersebut diantaranya dilakukan oleh Taylor dan Driffield (2004) dengan mengambil sampel di United Kingdom, Feenstra dan Hanson (1997) dengan mengambil sampel di Meksiko, serta Mah (2002) dengan mengambil sampel di Korea Selatan. Penelitian berikutnya menyatakan bahwa FDI tidak berpengaruh terhadap ketimpangan pendapatan. Penelitian ini diantaranya dilakukan oleh Lindert dan Williamson (2001) dan Milanovic (2002).

\section{Pengaruh FDI terhadap Tingkat Pengangguran}

Banyak penelitian yang meneliti pengaruh FDI terhadap tingkat pengangguran. Misalnya Massoud (2008) yang menemukan adanya pengaruh negatif antara FDI dengan tingkat pengangguran di Mesir. Kemudian, Habib dan Sarwar (2013) juga menemukan adanya pengaruh negatif antara FDI dengan tingkat pengangguran di Pakistan. Namun, dengan metode yang berbeda, Saray (2011) tidak menemukan adanya hubungan antara FDI dengan tingkat pengangguran di Turki.

\section{Perumusan Hipotesis}

Berdasarkan landasan teori dan penelitian se- belumnya yang telah diuraikan di atas, penulis mengambil beberapa hipotesis sebagai berikut:

H1: Foreign Direct Investment Inflows berpengaruh terhadap Ketimpangan Pendapatan di Indonesia

H2: Foreign Direct Investment Inflows berpengaruh terhadap tingkat pengangguran di Indonesia

\section{METODE PENELITIAN}

\section{Ruang Lingkup Penelitian}

Ruang lingkup pada penelitian ini mengambil tahun 2002-2015. Hal ini mengingat ketersediaan data berbagai variabel yang digunakan dalam penelitian ini pada website worldbank dan Badan Pusat Statistik.

\section{Teknik Pengumpulan Data}

Data yang digunakan dalam penelitian ini adalah data sekunder sehingga teknik pengumpulan data dilakukan adalah dengan cara mengunduh data pada situs-situs penyedia data seperti Badan Pusat Statistik maupun World Bank.

\section{Variabel Penelitian dan Cara Pengukuran}

\section{Variabel Dependen}

Terdapat dua variabel dependen yang akan diolah secara terpisah dalam penelitian ini yaitu Kesenjangan Pendapatan dan Tingkat Pengangguran. Kesenjangan pendapatan diukur dengan menggunakan proksi GINI ratio yang didapatkan dari situs Badan Pusat Statistik, kemudian tingkat pengangguran diukur dengan menggunakan proksi persentase unemployment terhadap jumlah tenaga kerja di Indonesia dengan menggunakan metode estimasi International Labour Organization (ILO).

\section{Variabel Independen}

Variabel independen dalam penelitian ini adalah Foreign Direct Investment inflow yang diukur dengan menggunakan proksi persentase FDI inflow terhadap Gross Domestic Product (GDP).

\section{Variabel Kontrol}

Variabel kontrol yang digunakan dalam penelitian ini adalah tingkat inflasi dan general government expenditure. Inflasi diukur dengan menggu- 
nakan proksi tingkat inflasi berdasarkan consumer price index, sedangkan government expenditure diukur dengan menggunakan proksi persentase general government final consumption expenditure terhadap GDP. General government final consumption expenditure adalah seluruh pengeluaran pemerintah dalam bentuk konsumsi barang/ jasa termasuk belanja pada bidang pertahanan dan keamanan negara.

\section{Teknik Analisis Data}

Teknik analisis yang digunakan dalam menjawab hipotesis pada bagian sebelumnya adalah regresi linear berganda ordinary least square. Sebelum penulis melakukan analisis regresi, penulis juga melakukan analisis statistik deskriptif, uji pengaruh simultan, dan uji asumsi klasik.

\section{Model Penelitian Awal}

Berdasarkan variabel-variabel di atas dan berdasarkan landasan teori yang ada, maka dapat disusun model penelitian awal sebagai berikut:

\section{Model 1 \\ $\mathrm{GINI}=\mathrm{c}+\mathrm{a} 1 \mathrm{FDI}+\mathrm{a} 2 \mathrm{INFL}+\mathrm{a} 3 \mathrm{EXP}+e$}

Model 2

$\mathrm{UNEMP}=\mathrm{c}+\mathrm{a} 2 \mathrm{FDI}+\mathrm{a} 2 \mathrm{INFL}+\mathrm{a} 3 \mathrm{EXP}+e$

Keterangan:

c $=$ Konstanta

$\mathrm{a} 1,2, \ldots=$ Koefisien regresi

e $=$ error

GINI $=$ GINI Ratio

FDI $=$ Persentase FDI Inflow terhadap GDP

INFL $=$ Tingkat Inflasi berdasarkan consumer price index

$\mathrm{EXP}=$ Persentase general government final consumption expenditure terhadap GDP

\section{HASIL DAN PEMBAHASAN}

\section{Pengambilan Sampel}

Sampel yang digunakan dalam penelitian ini adalah sampel time series dari tahun 2002-2015. Hal ini mengingat ketersediaan dan kelengkapan data pada website World Bank dan Badan Pusat Statistik.

\section{Transformasi Data}

Pada tahun 2002-2015 juga terdapat data yang tidak lengkap di beberapa tahun karena pada tahun tersebut tidak terdapat pendataan terkait dengan variabel yang datanya tidak lengkap tersebut. Untuk itu, jika penulis mendapatkan variabel yang pada suatu tahun tidak terdapat datanya, maka penulis akan melakukan asumsi dengan menarik garis lurus antara tahun-tahun yang terdapat datanya.

\section{Statistik Deskriptif}

Hasil analisis statistik deskriptif dengan menggunakan aplikasi SPSS 23 didapatkan hasil sebagai berikut:

Tabel 1

Statistik Deskriptif

\begin{tabular}{llrrrr}
\hline & N & Minimum & Maximum & Mean & $\begin{array}{c}\text { Std. } \\
\text { Deviation }\end{array}$ \\
\hline GINI & 14 &, 24 &, 29 &, 2626 &, 01832 \\
\hline UNEMP & 14 &, 06 &, 11 &, 0816 &, 01748 \\
\hline FDI & 14 &, 00 &, 03 &, 0168 &, 00995 \\
\hline INFL & 14 &, 04 &, 13 &, 0737 &, 02765 \\
\hline EXP & 14 &, 07 &, 10 &, 0877 &, 00715 \\
\hline $\begin{array}{l}\text { Valid N } \\
\text { (listwise) }\end{array}$ & 14 & & & & \\
\hline
\end{tabular}

\section{Uji F (Pengaruh Simultan)}

Berdasarkan uji F untuk model pertama dan kedua, maka didapatkan hasil yang dapat dilihat pada tabel 2 dan tabel 3 sebagai berikut:

Tabel 2

Hasil Uji F Model 1

\begin{tabular}{|c|c|c|c|c|c|c|}
\hline \multicolumn{2}{|c|}{ Model } & \multirow{2}{*}{$\begin{array}{r}\begin{array}{r}\text { Sum of } \\
\text { Squares }\end{array} \\
003\end{array}$} & \multirow{2}{*}{$\frac{\text { df }}{3}$} & \multirow{2}{*}{\begin{tabular}{r}
\multicolumn{1}{c}{$\begin{array}{c}\text { Mean } \\
\text { Square }\end{array}$} \\
, 001
\end{tabular}} & \multirow{2}{*}{$\frac{\mathbf{F}}{12,605}$} & \multirow{2}{*}{$\frac{\text { Sig. }}{, 001^{\mathrm{b}}}$} \\
\hline 1 & Regression & & & & & \\
\hline & Residual & ,001 & 10 & ,000 & & \\
\hline & Total & ,004 & 13 & & & \\
\hline
\end{tabular}

a. Dependent Variable: GINI

b. Predictors: (Constant), EXP, FDI, INFL

Tabel 3

Hasil Uji F Model 2

\begin{tabular}{|c|c|c|c|c|c|c|}
\hline \multicolumn{2}{|c|}{ Model } & $\begin{array}{l}\text { Sum of } \\
\text { Squares }\end{array}$ & df & \multirow{2}{*}{$\begin{array}{c}\text { Mean } \\
\text { Square }\end{array}$} & \multirow{2}{*}{$\begin{array}{l}\mathbf{F} \\
5,812\end{array}$} & \multirow{2}{*}{$\frac{\text { Sig. }}{, 015}$} \\
\hline 1 & Regression & ,003 & 3 & & & \\
\hline & Residual & ,001 & 10 & ,000, & & \\
\hline & Total & ,004 & 13 & & & \\
\hline
\end{tabular}

a. Dependent Variable: UNEMP

b. Predictors: (Constant), EXP, FDI, INFL 
Berdasarkan hasil uji F di atas, dapat disimpulkan pada model pertama seluruh variabel independen dan variabel kontrol secara bersama-sama mampu mempengaruhi secara signifikan variabel kesenjangan pendapatan. Sedangkan pada model kedua, juga dapat disimpulkan bahwa seluruh variabel independen dan variabel kontrol secara bersama-sama mampu mempengaruhi secara signifikan variabel tingkat pengangguran.

\section{Pengujian Hipotesis (Uji t)}

Setelah dilakukan uji asumsi klasik berupa uji normalitas, autokorelasi, heteroskedasitas dan multikolinearitas maka penulis melakukan pengujian hipotesis. Pengujian hipotesis dilakukan dengan menggunakan regresi linear beganda OLS melalui aplikasi statistik SPSS 23. Dalam penelitian ini, penulis menggunakan pendekatan Null Hypothesis Significance Testing (NHST). Untuk menentukan apakah H0 diterima atau ditolak, penulis akan menggunakan p-value (dalam aplikasi IBM SPSS 23 tertulis sig) dengan asumsi H0 adalah benar (Field, 2013, 2.6.1.3). Oleh karena itu, parameter yang penting untuk menguji hipotesis dalam penelitian ini adalah pada signifikansi variabel yang diteliti dan tanda koefisien pada masingmasing variabel.

Hasil analisis regresi dan uji t untuk hipotesis pertama (pengaruh FDI terhadap kesenjangan pendapatan) dapat dilihat pada Tabel 4 berikut:

Tabel 4

Analisis Regresi Berganda Hipotesis Pertama

\begin{tabular}{|c|c|c|c|c|c|c|}
\hline \multirow{2}{*}{\multicolumn{2}{|c|}{ Model }} & \multicolumn{2}{|c|}{$\begin{array}{c}\text { Unstandardized } \\
\text { Coefficients }\end{array}$} & \multirow{2}{*}{$\begin{array}{c}\text { Standardized } \\
\text { Coefficients } \\
\text { Beta }\end{array}$} & \multirow[b]{2}{*}{$\mathbf{t}$} & \multirow[b]{2}{*}{ Sig. } \\
\hline & & B & $\begin{array}{l}\text { Std. } \\
\text { Error }\end{array}$ & & & \\
\hline \multirow[t]{4}{*}{1} & (Constant) & ,151 & ,055 & & 2,744 & ,021 \\
\hline & FDI & ,823 & ,335 & ,447 & 2,454 & ,034 \\
\hline & INFL &,- 099 & ,127 &,- 149 &,- 777 & ,455 \\
\hline & EXP & 1,197 & ,587 & ,467 & 2,039 & ,069 \\
\hline
\end{tabular}

Berdasarkan Tabel 4 di atas, dapat dilihat bahwa berdasarkan uji t, dapat disimpulkan bahwa H1 harus diterima karena nilai sig. untuk variabel FDI berada di bawah 0,05 yang artinya FDI berpengaruh secara signifikan terhadap kesenjangan pendapatan di Indonesia. Pada tabel 4 juga dapat dilihat bahwa pengaruh tersebut adalah pengaruh positif yang artinya apabila FDI semakin meningkat maka kesenjangan pendapatan akan semakin meningkat pula.

Selanjutnya, Hasil analisis regresi dan uji t untuk hipotesis kedua (pengaruh FDI terhadap tingkat pengangguran) dapat dilihat pada tabel 5 sebagai berikut:

Tabel 5

Analisis Regresi Berganda Hipotesis Kedua

\begin{tabular}{|c|c|c|c|c|c|}
\hline \multirow[b]{2}{*}{ Model } & \multicolumn{2}{|c|}{$\begin{array}{l}\text { Unstandardized } \\
\text { Coefficients }\end{array}$} & \multirow{2}{*}{$\begin{array}{c}\begin{array}{c}\text { Standardized } \\
\text { Coefficients }\end{array} \\
\text { Beta }\end{array}$} & \multirow[b]{2}{*}{$\mathbf{t}$} & \multirow[b]{2}{*}{ Sig. } \\
\hline & B & $\begin{array}{l}\text { Std. } \\
\text { Error }\end{array}$ & & & \\
\hline 1 (Constant) & ,194 & ,069 & & 2,804 &, 019 \\
\hline FDI &,- 139 & ,422 &,- 079 &,- 330 &, 749 \\
\hline INFL & 160 & 160 & ,253 & ,998 & 342 \\
\hline EXP & $-1,393$ & ,739 &,- 570 & $-1,885$ & ,089 \\
\hline
\end{tabular}

a. Dependent Variable: UNEMP

Berdasarkan Tabel 5 di atas, dapat dilihat bahwa berdasarkan uji t, dapat disimpulkan bahwa H1 harus ditolak karena nilai sig. untuk variabel FDI berada di atas 0,05 yang artinya FDI tidak berpengaruh terhadap tingkat pengangguran di Indonesia.

\section{PEMBAHASAN}

Berdasarkan hasil analisis pada bagian sebelumnya, dapat dilihat bahwa FDI berpengaruh positif secara signifikan terhadap kesenjangan pendapatan, artinya, semakin besar FDI maka kesenjangan pendapatan akan semakin meningkat. Hal ini sesuai dengan penelitian Taylor dan Driffield (2004) yang mengambil sampel di United Kingdom, Feenstra dan Hanson (1997) yang mengambil sampel di Meksiko, serta Mah (2002) yang mengambil sampel di Korea Selatan.

Hal ini tentunya menjadi suatu temuan baru bahwa adanya FDI di Indonesia belum mampu memberikan pengaruh baik pada masyarakat dengan mengurangi jurang kesenjangan pendapatan, namun malah menambah jurang kesenjangan itu sendiri. Hal ini diperkuat dengan hasil pengujian hipotesis kedua dimana FDI tidak berpengaruh terhadap tingkat pengangguran, padahal pemerintah mengharapkan untuk mengurangi tingkat pengangguran dengan menggalakkan adanya investasi dari luar negeri.

Salah satu hal yang menyebabkan adanya 
fenomena ini adalah karena perusahaan multinasional di Indonesia lebih suka untuk mengambil tenaga kerja terdidik (yang akan diberi penghasilan besar) dan meninggalkan tenaga kerja yang tidak terdidik atau jika ada perusahaan multinasional yang menggunakan tenaga kerja tidak terdidik, maka akan diberi penghasilan yang rendah yang tentunya hal ini semakin meningkatkan jurang kesenjangan pendapatan di Indonesia. Padahal, salah satu syarat keberhasilan suatu negara untuk mengurangi kesenjangan pendapatan dengan cara menggalakkan adanya FDI adalah adanya FDI tersebut harus mampu menyerap tenaga kerja tidak terdidik di suatu negara (Deardorff dan Stern, 1994).

\section{KESIMPULAN}

Dewasa ini, pemerintah sedang gencar-gencarnya meningkatkan investasi di dalam negeri. Salah satu tujuan pemerintah meningkatkan investasi adalah agar pengangguran dan kesenjangan pendapatan dapat berkurang. Hal tersebut tentu menimbulkan pertanyaan, apakah FDI yang sedang digalakkan pemerintah ini memang dapat dengan efektif mengurangi kesenjangan pendapatan dan tingkat pengangguran? Berdasarkan hasil analisis regresi didapatkan bahwa FDI berpengaruh positif terhadap kesenjangan pendapatan dan tidak berpengaruh terhadap tingkat pengangguran. Hal ini menegaskan bahwa pada dasarnya FDI tidak memberikan efek yang baik pada Indonesia, terbukti dengan adanya FDI tidak mampu memberikan pengaruh pada tingkat penganggu- ran dan di sisi lain dapat semakin meningkatkan kesenjangan pendapatan di Indonesia. Salah satu hal yang menyebabkan adanya fenomena ini adalah karena perusahaan multinasional di Indonesia lebih suka untuk mengambil tenaga kerja terdidik (yang akan diberi penghasilan besar) dan meninggalkan tenaga kerja yang tidak terdidik atau jika ada perusahaan multinasional yang menggunakan tenaga kerja tidak terdidik, maka akan diberi penghasilan yang rendah yang tentunya hal ini semakin meningkatkan jurang kesenjangan pendapatan di Indonesia.

\section{SARAN}

Oleh karena itu, berdasarkan simpulan tersebut, penulis ingin memberikan saran kepada pengambil kebijajkan terkait dengan pengaturan FDI (Perusahaan Multinasional) sebagai berikut:

1. Pemerintah harus membuat suatu regulasi agar perusahaan multinasional tetap memperkerjakan tenaga kerja tidak terdidik selain memperkerjakan tenaga kerja terdidik;

2. Pemerintah harus membuat suatu program untuk meningkatkan skill masyarakat Indonesia agar mampu bersaing untuk bekerja di perusahaan multinasional;

3. Pemerintah harus memberikan pengawasan yang ketat kepada perusahaan multinasional, baik terkait sisi perpajakan, penggunaan sumber daya, maupun pemanfaatan tenaga kerja Indonesia agar dapat memberikan nilai tambah yang maksimal bagi Indonesia. 


\section{REFERENSI}

Choi, Changkyu. 2006. "Does Foreign Direct Investment Affect Doemestic Income Inequality?” Applied Economics Letters 13 811-814.

Deardorff, A., dan R. Stern. 1994. The Stolper-Samuelson Theorem: A golden Jubilee. Ann Arbor: University of Michigan Press.

Feenstra, R.C., dan G.H. Hanson. 1997. "Foreign Direct Investment and Relative Wages: Evidence from Mexico's Maquiladoras." Journal of International Economics 42 371-393.

Habib, M.D., dan S. Sarwar. 2013. "Impact of Foreign Direct Investment on Employement Level in Pakistan: A Time Series Analysis." Journal of Law, Policy, and Globalization Vol 10 46-55.

Lindert, P.H., dan J.G. Williamson. 2001. "Does Globalization Make The World More Unequal?" NBER Working Paper 8228.

Mah, J.S. 2002. "The Impact of Globalization on Income Distribution: The Korean Experience." Applied Economics Letters 0 1007-1009.

Massoud, N. 2008. "Assessing The Employment Effect of FDI Inflows to Eqypt: Does The Mode of Entry Matter?" International Conference on "The Unployment Crisis in The Arab Countries".

Milanovic, B. 2002. "Can We Discern the Effect of Globalization on Income Distribution? Evidence from Household Budget Surveys.” World Bank Policy Research Working Paper 876.

Saray, M.O. 2011. "The Relationship of Foreign Direct Investment and Employment: Turkey Case." Maliye Dergisi 161 381-403.

Taylor, K., dan N. Driffield. 2004. "Wage Inequality and The Role of Multinationals: Evidence From UK Panel Data." Labour Economics.

Tsai, P.L. 1995. "Foreign Direct Investment and Income Inequality: Further Evidence.” World Develoment 23 469-483.

Wahyuni, I Gusti Ayu Putri, Made Sukarsa, dan Nyoman Yuliarmi. 2014. "Pengaruh Pengeluaran Pemerintah dan Investasi terhadap Pertumbuhan Ekonomi dan Kesenjangan Pendapatan Kabupaten/ Kota di Provinsi Bali.” E-Jurnal Ekonomi dan Bisnis Universitas Udayana 458-477. 
